\title{
Multiple electroconvulsive shocks and disruption of estrus
}

\author{
SAMUEL N. GREEN \\ University of Georgia, Athens, Georgia 30601
}

and

\author{
MARGARET SEATON, R. CRAIG WILLIAMS, and JOEL S. MILNER \\ Western Carolina University, Cullowhee, North Carolina 28723
}

\begin{abstract}
The effects of increasing numbers of electroconvulsive shock (ECS) treatments on the estrous cycle in the rat were investigated. Seventy-six female Sprague-Dawley rats were selected on the basis of stability of estrus from an initial subject pool. The rats were assigned randomly to one of eight treatment conditions, with the restriction that each treatment condition contain 14 subjects and each control condition contain 5 subjects. Treatment conditions were as follows: 5 ECSs, 10 ECSs, 15 ECSs, and 20 ECSs; 5 sham ECSs (SECSs), 10 SECSs, 15 SECSs, and 20 SECSs. Results indicated that all ECS conditions produced a significant delay in the onset of estrus following treatment. No additional delays in estrus were observed once estrus resumed.
\end{abstract}

Milner, Gilbert, and Prewett (1978) report that multiple electroconvulsive shocks (ECSs) disrupt the reproductive cycle in rats. Specifically, they found that while one ECS treatment does not affect estrus, five ECS treatments significantly delay the onset of estrus. Milner and Green (1980) studied the effects of one, two, three, four, and five ECS treatments to determine the minimum number of shocks required to produce the disruption of estrus in the rat. They report that both one and two ECS treatments do not affect estrus, whereas three, four, and five ECS treatments significantly delay estrus. In both studies (Milner et al., 1978; Milner \& Green, 1980), once estrus began following ECS treatments, no additional delays of estrus were observed.

The purpose of the present study was to investigate the effects of increasing numbers of ECS treatments on estrus in the rat. The study sought to determine if increasing the number of shocks can increase the duration of the initial delay of estrus and produce additional delays in estrus in subsequent reproductive cycles.

\section{METHOD}

\section{Subjects}

Eighty-one naive female Sprague-Dawley albino rats, 57 days of age, served as the initial subject pool. Each rat was housed in a stainless steel cage that measured $40 \times 24 \times 19 \mathrm{~cm}$, and all animals were maintained on an ad-lib food and water schedule.

\section{Apparatus}

A Grason-Stadler shocker was employed to deliver ECS, which consisted of a 30-mA constant current of $.5 \mathrm{sec}$ duration from a $28-\mathrm{V}(50-$ to $60-\mathrm{Hz})$ power source. Shock was delivered via saline-soaked gauze-covered ear clips and was sufficient to

Requests for reprints should be sent to Joel S. Milner, Department of Psychology, Western Carolina University, Cullowhee, North Carolina 28723. induce a complete tonic-clonic convulsion. Sham ECS (SECS) consisted of attaching the saline-soaked gauze-covered ear clips for approximately $5 \mathrm{sec}$ without delivery of shock.

\section{Procedure}

Following habituation to the laboratory for 7 days, all rats were given daily vaginal smears for a period of 60 days. Seventysix rats were chosen from the initial subject pool on the basis of stability of estrus. Stable estrus was defined as continuous cycling on a regular interval basis for at least six complete cycles immediately preceding application of treatment. The 76 rats were assigned randomly to one of eight treatment conditions, with the restriction that each ECS condition contain 14 subjects and each SECS condition contain 5 subjects. The treatment conditions were as follows: 5 ECSs, 10 ECSs, 15 ECSs, and 20 ECSs; 5 SECSs, 10 SECSs, 15 SECSs, and 20 SECSs.

At 114 days of age, the subjects received one of the eight treatment conditions. Rats in both the ECS and SECS groups received treatments at $48 \mathrm{~h}$ intervals until treatments were completed. Vaginal smears were continued every day during and following treatments. Data on the estrous cycle were recorded until all subjects completed three estrous cycles.

\section{RESULTS}

An analysis of variance indicated no significant differences $[F(7,68)=1.00, p>.05]$ between treatment conditions in the mean number of days of the estrous cycles during the pretreatment period. During treatment, one rat in the 15-ECS condition died from undetermined etiology following the 13th shock. Thus, in the following analysis of the posttreatment data, the total sample size was reduced from 76 to 75 subjects.

The mean number of days until the onset of estrus after each treatment, between the first and second estrus, and between the second and third estrus are presented in Table 1. Since all rats were administered ECS and SECS on the same days, the treatments would be expected to be distributed randomly across estrous 
Table 1

Mean Days Until the Onset of Estrus After ECS and SECS for Each of the Treatment Conditions

\begin{tabular}{|c|c|c|c|c|c|c|c|c|c|c|c|c|}
\hline \multirow{4}{*}{$\begin{array}{c}\text { Condi- } \\
\text { tion }\end{array}$} & \multicolumn{12}{|c|}{ Interval (in Days) } \\
\hline & \multicolumn{6}{|c|}{ ECS Conditions } & \multicolumn{6}{|c|}{ SECS Conditions } \\
\hline & \multicolumn{2}{|c|}{$\begin{array}{c}\text { Treatment to } \\
\text { First Estrus }\end{array}$} & \multicolumn{2}{|c|}{$\begin{array}{c}\text { First to } \\
\text { Second Estrus }\end{array}$} & \multicolumn{2}{|c|}{$\begin{array}{l}\text { Second to } \\
\text { Third Estrus }\end{array}$} & \multicolumn{2}{|c|}{$\begin{array}{l}\text { Treatment to } \\
\text { First Estrus }\end{array}$} & \multicolumn{2}{|c|}{$\begin{array}{c}\text { First to } \\
\text { Second Estrus }\end{array}$} & \multicolumn{2}{|c|}{$\begin{array}{l}\text { Second to } \\
\text { Third Estrus }\end{array}$} \\
\hline & Mean & $\mathrm{SE}$ & Mean & SE & Mean & $\mathrm{SE}$ & Mean & $\mathrm{SE}$ & Mean & SE & Mean & SE \\
\hline 5 & 10.29 & .81 & 4.36 & .17 & 4.21 & .16 & 2.20 & .58 & 4.00 & .00 & 5.00 & .00 \\
\hline 10 & 13.29 & 1.46 & 4.50 & .25 & 4.50 & .20 & 2.20 & .20 & 3.80 & .20 & 4.20 & .20 \\
\hline 15 & 15.00 & 2.49 & 5.39 & .90 & 4.63 & .18 & 3.40 & .60 & 4.40 & .51 & 4.40 & .24 \\
\hline 20 & 18.07 & 1.98 & 4.43 & .20 & 4.93 & .59 & 2.80 & .73 & 5.00 & .32 & 5.20 & 1.20 \\
\hline
\end{tabular}

cycles. Thus, in each group, the number of days between the last treatment and the onset of the first estrus should be approximately one-half of the mean estrous cycle length if no treatment effect is present.

Analysis of variance showed a significant difference $[F(7,67)=10.34, p<.01]$ between treatment conditions in the number of days before the onset of estrus following treatment. A Newman-Keuls multiple-range test indicated significantly $(p<.05)$ more days until the onset of estrus in all of the ECS treatment conditions relative to the SECS treatment conditions. In addition, the Newman-Keuls test indicated the 20-ECS treatment condition significantly $(p<.05)$ delayed the onset of estrus beyond the delay of the 5-ECS treatment condition.

Analysis of variance indicated there was no significant difference $[F(7,67)=1.02, p>.05]$ between treatment conditions in the number of days between the first and second estrus following treatment. Another analysis of variance showed no significant differences $[F(7,67)=$ $.86, \mathrm{p}>.05$ ] between treatment conditions in the number of days between the second and third estrus following ECS.

\section{DISCUSSION}

The analysis indicates that all ECS treatments produced a significant delay in the onset of estrus. Further, 20 ECS treatments produced a delay in the onset of estrus that was significantly greater than that produced by 5 ECS treatments, but not greater than the delay produced by 10 or 15 ECS treatments. The data for the individual animals indicated that one, one, two, and one rats in the 5-, 10-, 15-, and 20-ECS groups, respectively, did not exhibit a delay in estrus. Once estrus began following ECS, no additional delays in estrus were observed.

The observation by Milner et al. (1978) and Milner and Green (1980) that five ECS treatments significantly delay the onset of estrus was supported by the present data. The data also indicate that increasing the number of ECS treatments to 20 will produce a further delay in the onset of estrus. However, increasing the number of ECS treatments to 20 does not produce any additional delays in estrus once estrus begins following treatment.

\section{REFERENCES}

Milner, J. S., Gilbert, L. F., \& Prewett, M. J. Electroconvulsive shock and the estrous cycle in the rat. Behavioral Biology, 1978, 24, 279-283.

Milner, J. S., \& Green, S. N. The relationship between the number of electroconvulsive shock treatments and estrous disruption. Physiology \& Behavior, 1980, 25, 323-325. 